\title{
LPS-induced upregulation of the TLR4 signaling pathway inhibits osteogenic differentiation of human periodontal ligament stem cells under inflammatory conditions
}

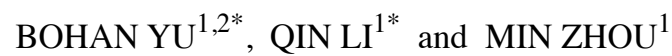 \\ ${ }^{1}$ Department of Cosmetic Dentistry, School and Hospital of Stomatology, Tongji University, \\ Shanghai Engineering Research Center of Tooth Restoration and Regeneration; ${ }^{2}$ Department of Periodontology, \\ Affiliated Stomatology Hospital of Tongji University, Shanghai 200072, P.R. China
}

Received September 10, 2018; Accepted February 25, 2019

DOI: $10.3892 /$ ijmm.2019.4165

\begin{abstract}
Toll-like receptor 4 (TLR4) is a transmembrane receptor responsible for the activation of a number of signal transduction pathways. Despite its involvement in inflammatory processes, the regulation of TLR4 signaling in human periodontal ligament stem cells (hPDLSCs) under inflammatory conditions remains to be fully elucidated. The present study aimed to clarify the regulatory mechanisms of the TLR4 signaling pathway and its role in the differentiation of hPDLSCs under inflammatory conditions. hPDLSCs from the periodontal tissues of healthy subjects and patients with periodontitis were identified by analyzing their cell surface marker molecules, and their osteogenic and adipogenic differentiation abilities. To determine the effect of TLR4 signaling on osteogenic and adipogenic differentiation under inflammatory conditions, cells were challenged with TLR4 agonist and antagonist under pluripotent differentiation conditions. Cell proliferation, apoptosis and migration were then determined using appropriate methods. The alkaline phosphatase (ALP) activity, Alizarin Red staining, Oil red O staining and relative gene and protein levels expression were also determined. The results showed that lipopolysaccharide (LPS)-induced inflammation inhibited cell proliferation and migration, promoted cell apoptosis and affected the cell cycle. Under inflammatory conditions, the activation of TLR4 decreased the activity of ALP and the expression of osteogenic markers, including osteocalcin, Runt-related transcription factor 2 and collagen I, compared with the control group, but increased the expression
\end{abstract}

Correspondence to: Dr Bohan Yu, Department of Periodontology, Affiliated Stomatology Hospital of Tongji University, 399 Yanchang Road, Shanghai 200072, P.R. China

E-mail: bhyu198312@163.com

${ }^{*}$ Contributed equally

Key words: Toll-like receptor 4, osteogenic differentiation, periodontal ligament stem cells, inflammation of adipogenesis-related genes poly (ADP-ribose) polymerase $\gamma$ and lipoprotein lipase. The activation of TLR4 also induced the expression of proinflammatory cytokines interleukin-1 $\beta$, tumor necrosis factor- $\alpha$, nuclear factor- $\kappa$ BP65 and TLR4, compared with that in the control group and the TLR4 antagonist group. The findings showed that LPS-induced upregulation of the TLR4 signaling pathway inhibited osteogenic differentiation and induced adipogenesis of the hPDLSCs under inflammatory conditions. The present study provided a novel understanding of the physiopathology of periodontitis, and a novel avenue for targeted treatments based on stem cell regeneration.

\section{Introduction}

Periodontal disease is a chronic inflammatory disease and the major cause of teeth loss in adults (1). The pathogenesis of periodontal disease is due to the microorganisms that adhere to and grow on the surfaces of teeth or periodontal tissues, triggering chronic inflammatory reactions and subsequently damaging the connection of periodontal soft tissues to facilitate the absorption of alveolar bone. This leads to destruction of the structures supporting the teeth and eventual tooth loss $(2,3)$. Currently, there are no effective treatment methods for periodontal disease. The periodontal ligament contains a group of pluripotent periodontal stem cells, which can express surface markers of mesenchymal stem cells with the characteristics of self-renewal and pluripotency (4). Human periodontal ligament stem cells (hPDLSCs) can differentiate to form bones, cartilage, neurons, adipocytes and blood vessel tissues via in vitro induction, and can form a cementum-periodontal ligament-alveolar bone-like structure following in vivo implantation (5-8). This indicates that hPDLSCs have significant involvement in the reconstruction, regeneration and fixation of periodontal tissue. hPDLSCs were isolated for the first time from the third molar periodontal ligament by Seo et al (9). hPDLSCs are also found on the inner surface of the tooth socket following tooth extraction (10). Highly purified hPDLSCs clones have also been extracted from periodontal tissues (11); studies have purified hPDLSCs from inflammatory periodontal ligament tissue and confirmed their potential to regenerate cementum and periodontal ligament (12). Studies have revealed 
novel ways of obtaining purified hPDLSCs from suppressed periodontal ligaments (13-16). Furthermore, studies have shown that the periodontal inflammatory microenvironment can destroy periodontal tissue by suppressing the regeneration ability of hPDLSCs; however, the underlying mechanism remains to be elucidated (17).

Due to their proliferation and pluripotent differentiation ability, and their capacity to form Sharpey's fibres and cementum-like structures, hPDLSCs are considered the optimal seeding cells in periodontal engineering (18). The co-implantation of hPDLSCs with hydroxyapatite or $\beta$-tricalcium phosphate scaffold in nude mice allowed the formation of periodontal ligament- and cementum-like structures (9). In addition, animal experiments have revealed that multiple PDLSCs from different sources, including human, canine and swine sources, can initiate the homing effects and facilitate the regeneration of periodontal tissue following implantation (19-21). Dentin non-collagen proteins can increase the proliferation and adhesion abilities, facilitate morphological changes, increase alkaline phosphatase (ALP) activity and induce the differentiation of hPDLSCs into cementoblasts (22). As hPDLSCs cannot express human leukocyte antigen II or co-stimulatory molecules, it is hypothesized that the underlying mechanism of hPDLSC immunosuppression may be achieved by prostaglandin 2-mediated $\mathrm{T}$ cell non-responsiveness (23). Therefore, studies investigating periodontal disease should focus on investigating the molecular mechanisms involved in the osteogenic differentiation of hPDLSCs in the chronic inflammatory microenvironment, in order to provide a theoretical basis for optimizing the stem cell-mediated treatment of periodontal inflammatory diseases.

Toll-like receptors (TLRs) are a class of transmembrane receptors, which can recognize and bind the corresponding pathogen-associated molecular patterns, activate the signal transduction pathway and induce the expression of certain immune effector molecules, including inflammatory cytokines (24). TLRs are type I transmembrane proteins and can be divided into three structural parts: Extracellular, cytoplasmic and transmembrane. The extracellular domain of TLRs are responsible for receptor recognition and the binding to other auxiliary receptors to form a receptor complex $(25,26)$. TLR4, the first identified mammalian TLR, is expressed in all cell lines. Findings indicate that TLR4 is important in pro-inflammatory reactions, promoting the maturation and differentiation of immune cells, and regulating immune responses (27). TLR4 is involved in the inflammatory response to ischemia-reperfusion injury in vivo. TLR4 is also involved in the apoptosis of various cell types, including immune cells, hepatocytes, cardiomyocytes, gastric cancer cells, breast cells, renal tubular epithelial cells and airway smooth muscle cells (28). Studies have demonstrated that mice with deficient TLR4 function exhibit significantly lower ischemia damage compared with wild-type mice. The inhibition of TLR4 can reduce ischemia-reperfusion injury by regulating apoptosis (29). As a member of the TLR family, TLR4 is a receptor of lipopolysaccharide (LPS) and lipid A in Gram-negative bacteria. When LPS is bound together with TLR4, a cascade of signaling pathways is triggered which can activate the expression of type I interferons (IFN- $\alpha$ and IFN- $\beta$ ), pro-inflammatory cytokines, including interleukin (IL)-1, IL-6 and tumor necrosis factor (TNF)- $\alpha$, and chemotactic cytokine IL-8 (30). Previous studies have indicated that the LPS-induced activation of hPDLSCs is followed by activation of the TLR4/MyD88 complex, which causes the release of cytokines, including IL-1 $\alpha$, IL-8 and TNF- $\alpha$ (31). However, the exact role of TLR4 in the differentiation of hPDLSCs, particularly under inflammatory conditions, and the underlying molecular mechanisms have not been investigated in detail.

The present study aimed to investigate the regulatory roles of TLR4 in the osteogenic and adipogenic differentiation of hPDLSCs under inflammatory conditions, in order to reveal the regulatory role of the TLR4 signaling pathway in stem cell osteogenic differentiation. This may lay a foundation for the diagnosis and treatment of the chronic inflammatory processes and tissue engineering.

\section{Materials and methods}

Isolation and primary culture of hPDLSCs. Specimens were collected from patients who underwent orthodontic teeth extraction in the Department of Oral and Maxillofacial Surgery of Hospital of Stomatology, Tongji University. The specimens were divided into two groups of 10 samples: The control group comprised patients without decayed teeth, apical periodontitis or periodontitis, and the experimental group comprised patients with periodontal inflammation. Briefly, following orthodontic extraction, the teeth were transferred into the culture medium and the tooth roots were repeatedly washed with antibiotic-containing PBS to remove the clotted blood. Subsequently, two-thirds of the periodontal membranes in the roots were scraped, and transferred into centrifuge tubes following thorough cutting with scissors. To each tube, $3 \mathrm{ml}$ of $0.1 \%$ collagenase was added, and the tube was shaken and digested at $37^{\circ} \mathrm{C}$ for $50-60 \mathrm{~min}$. Subsequently, $1 \%$ trypsin was added for further digestion for $25 \mathrm{~min}$. Thereafter, a small volume of $10 \%$ FBS was added to terminate the digestion. Following centrifugation at $700 \mathrm{x} g$ for $10 \mathrm{~min}$ at room temperature, the supernatant was discarded and then inoculated into a culture flask. An appropriate quantity of $\alpha$-MEM culture medium supplemented with $10 \%$ FBS (Gibco; Thermo Fisher Scientific, Inc., Waltham, MA, USA) was added and placed in an incubator containing 5\% $\mathrm{CO}_{2}$ at $37^{\circ} \mathrm{C}$ in saturated humidity. The medium was replaced every 2-3 days and the cells were sub-cultured when they grew to confluence. Finally, the original medium was discarded and the cells were washed with PBS; the cells were then examined under an inverted microscope. In order to examine changes between the normal and malignant/differentiation conditions, only hPDLSCs from healthy subjects were used in the subsequent experiments.

Purification of periodontal membrane stem cells by flow cytometry. Third passage hPDLSCs were collected, washed with PBS and digested with trypsin. A cell suspension was prepared at a density of $1 \times 10^{6}$ cells $/ \mathrm{ml}$ and dispensed into a sterilized EP tube $(1.5 \mathrm{ml})$. The fluorescently marked anti-human Stro-1-APC (cat. no. MA5-28635), CD146-FITC (cat. no. 11-1469-42), CD90-APC (cat. no. 17-0909-42), CD105-PE (cat. no. 12-1051-82), CD29-FITC (cat. no. 11-0291-82), CD31-APC (cat. no. 17-0311-82) and CD45-PE 
(cat. no. 12-0459-41) antibodies (1:10; all from Thermo Fisher Scientific, Inc.) were added to each tube, separately. The cells were incubated on ice for $1.5 \mathrm{~h}$ and subsequently centrifuged at $700 \mathrm{x} g$ for $3 \mathrm{~min}$ at room temperature. Finally, the supernatant was discarded and the cells were washed with PBS three times, re-suspended in $3 \% \mathrm{FBS}$ and subjected to flow cytometric analysis.

Immunohistochemistry and immunofluorescence of hPDLSCs. The well-grown cells were collected to prepare slides and fixed in $4 \%$ paraformaldehyde for $30 \mathrm{~min}$, and TLR4 and Stro-1 were stained for using the immunochemical SABC method. Briefly, following washing three times with PBS ( 2 min each time), the cells were incubated with $3 \%$ Triton-100 solution for 15 min to increase cell permeability. Subsequently, $3 \%$ hydrogen peroxide-methanol solution was added for $15 \mathrm{~min}$ to eliminate the effect of endogenous peroxidase. The cells were then washed three times with PBS, and normal goat serum (Sigma-Aldrich; Merck KGaA, Darmstadt, Germany) blocking solution was added for 15 min to eliminate non-specific staining. Following this, primary antibodies against TLR4 (polyclonal antibody; cat. no. sc-293072; 1:300; Santa Cruz Biotechnology, Inc., Dallas, TX, USA), keratin (polyclonal antibody; cat. no. PA5-68042; 1:300; Thermo Fisher Scientific, Inc.); Stro-1 (rabbit anti-human antibody; cat. no. sc-47733; 1:100; Santa Cruz Biotechnology, Inc.) were added. For the negative control, PBS was used instead of primary antibody and transferred to a refrigerator at $4^{\circ} \mathrm{C}$ overnight. Following rewarming in a $37^{\circ} \mathrm{C}$ incubator for $1 \mathrm{~h}$ and washing with PBS (5 min, three times), biotinylated secondary antibody (cat. no. ab6788; 1:1,000; Abcam, Cambridge, UK) was added at $37^{\circ} \mathrm{C}$ for $1 \mathrm{~h}$. Following this, a 1:50 dilution of FITC-labeled goat anti-rabbit IgG (cat. no. sc-2040; 1:50; Santa Cruz Biotechnology, Inc.) was added in the Stro-1 immunofluorescence group. Following washing with PBS and rinsing with distilled water, $500 \mathrm{ml}$ of non-fluorescent buffer glycerol was used for sealing in the Stro-1 immunofluorescence group, whereas SABC reagent was added to the other two groups, and incubated in a $37^{\circ} \mathrm{C}$ incubator for $20 \mathrm{~min}$. Following DAB staining and hematoxylin staining, examination was performed under an optical microscope.

MTT assay. The fourth passage isolated hPDLSCs were sub-cultured in 96-well plates at a density of $2 \times 10^{3}$ cells $/ \mathrm{ml}$ per well (six replicates) in an incubator containing $5 \% \mathrm{CO}_{2}$ at $37^{\circ} \mathrm{C}$. Therefore, $20 \mu \mathrm{l}$ of $0.5 \%$ MTT solution was added every day at a fixed time point, followed by incubation for $4 \mathrm{~h}$. This step was repeated for 14 days. In each case, when culture was stopped, the medium was carefully removed and $150 \mu \mathrm{l}$ of DMSO was added into each well. The cultures were then shaken at a low speed for $10 \mathrm{~min}$ to completely dissolve the crystals. Finally, the absorbance was measured at $490 \mathrm{~nm}$ using a spectrophotometric approach.

Cell cycle analysis. Cells were collected in the logarithmic grow th phase, counted with a hemocy tometer and inoculated into 6 -well plates at a density of $5 \times 10^{5}$ cells $/ \mathrm{ml}$. From this, $\sim 1 \times 10^{6}$ cells were collected and transferred into a centrifuge tube. Following centrifugation at $700 \mathrm{x} \mathrm{g}$ for $5 \mathrm{~min}$ at room temperature, the supernatant was discarded and the cells were washed with PBS and resuspended with $0.5 \mathrm{ml}$ PBS in the tube. Subsequently, $75 \%$ cold ethanol was added and mixed, followed by storage at $-20^{\circ} \mathrm{C}$ for $24 \mathrm{~h}$. During the assay, the ethanol was discarded by centrifugation, washed with PBS and resuspended with $1 \mathrm{ml}$ PBS. RNase $(5 \mu 1$, $10 \mathrm{mg} / \mathrm{ml}$ ) was added and followed by incubation in a water bath at $37^{\circ} \mathrm{C}$ for $1 \mathrm{~h}$. Propidium iodide (PI; $5 \mu 1,10 \mathrm{mg} / \mathrm{ml}$ ) was then added, followed by incubation at room temperature for $30 \mathrm{~min}$ in the dark. Finally, the cell cycle was detected by flow cytometry.

Pluripotency induction. Cells at logarithmic growth phase were cultured at a density of $2 \times 10^{4}$ cells $/ \mathrm{ml}$ in a six-well plate with coverslips in an incubator at $37^{\circ} \mathrm{C}$ containing $5 \% \mathrm{CO}_{2}$. The medium was replaced every 3 days, and when the cells reached $60 \%$ confluence, the culture medium was replaced with osteogenic, chondrogenic and adipogenic culture medium. The conventional standard medium was used as a control. The cells were collected on the 14th day and the medium was discarded. Fixation was performed using $4 \%$ formaldehyde (for Alizarin Red S staining) or formalin (Oil Red O staining) for $15 \mathrm{~min}$ at room temperature followed by washing (twice) with PBS. The cells were finally stained with Alizarin Red S and Oil Red O, respectively, and were visualized and analyzed under a microscope.

ALP assays. ALP activity was assessed using an ALP assay kit. The cells were washed and, following measurement of the cell concentration, $50 \mu \mathrm{l}$ of the assay buffer was added and followed by centrifugation at $11,900 \mathrm{x}$ g for $3 \mathrm{~min}$ at $4{ }^{\circ} \mathrm{C}$. Following this, $50 \mu \mathrm{l}$ of $5 \mathrm{mM}$ PNPP reaction solution was added to each well and reacted at $60^{\circ} \mathrm{C}$ for $60 \mathrm{~min}$ in the dark. Finally, $20 \mu \mathrm{l}$ of the stop solution was added and mixed, and the values of absorbance were measured at $405 \mathrm{~nm}$. Each assay condition was performed in triplicate and the results were repeated in at least three independent experiments. ALP activity was normalized by total cellular protein concentrations among the samples.

Reverse transcription-quantitative polymerase chain reaction $(R T-q P C R)$ analysis. Total RNA was extracted from the hPDLSCs of the normal and inflammation groups using TRIzol reagent and reverse transcribed into cDNA. PCR primers (Table I) were designed using the Primer3 program (http://bioinfo.ut.ee/primer3-0.4.0/). SYBR-Green-based qPCR analysis was performed to amplify the genes of interest using the RG-3000 Real-Time DNA Detection system (Corbett Research; Qiagen, Inc., Valencia, CA, USA). Triplicate reactions were performed for each sample. The amplification system was as follows: Power SYBR ${ }^{\circledR}$-Green Master Mix $10 \mu 1$, Forward Primer $(10 \mu \mathrm{M}) 0.5 \mu \mathrm{l}$, Reverse Primer $(10 \mu \mathrm{M}) 0.5 \mu \mathrm{l}$, cDNA $1 \mu \mathrm{l}, \mathrm{ddH}_{2} \mathrm{O}$ up to $20 \mu \mathrm{l}$. The amplification conditions were as follows: $94^{\circ} \mathrm{C}$ for $2 \mathrm{~min}$ for one cycle and 30 cycles at $92^{\circ} \mathrm{C}$ for $20 \mathrm{sec}, 57^{\circ} \mathrm{C}$ for $30 \mathrm{sec}$, and $72^{\circ} \mathrm{C}$ for $20 \mathrm{sec}$, followed by extension at $78^{\circ} \mathrm{C}$ for each cycle. The relative expression levels of OCN, RUNX2, LPL, COLI, TLR4, NF-кBP65, ALP, PPAR $\gamma$ were calculated using the $2^{-\Delta \Delta \mathrm{Cq}}$ method (32). All samples were run in triplicate and normalized by the endogenous expression level of GAPDH. 
Table I. Primer sequences.

\begin{tabular}{|c|c|c|c|}
\hline Primer & Sequence (5'-3') & Temperature $\left({ }^{\circ} \mathrm{C}\right)$ & Gene size (bp) \\
\hline GAPDH-F & CCTGCACCACCAACTGCTTA & 60.54 & 144 \\
\hline GAPDH-R & CATCACGCCACAGCTTTCCA & 61.24 & \\
\hline OCN-F & ATTGTGACGAGCTAGCGGAC & 60.18 & 131 \\
\hline OCN-R & TCGAGTCCTGGAGAGTAGCC & 60.11 & \\
\hline RUNX2-F & TGGCCGGGAATGATGAGAAC & 60.11 & 79 \\
\hline RUNX2-R & TTGAACCTGGCCACTTGGTT & 60.03 & \\
\hline LPL-F & CATGCAAGAACGGTGCCAAG & 59.96 & 169 \\
\hline LPL-R & CTCACAGTGATGGCCTGTGT & 59.96 & \\
\hline COLI-F & TGCGACAGTCTGGATGTCTT & 59.03 & 184 \\
\hline COLI-R & TGAAGGACCCGGATTTCACG & 60.04 & \\
\hline TLR4-F & TGTATCGGTGGTCAGTGTGC & 60.04 & 172 \\
\hline TLR4-R & CAGCTCGTTTCTCACCCAGT & 59.97 & \\
\hline NF-кBP65-F & GATCCTTTCGGAACTGGGCA & 60.04 & 113 \\
\hline NF-кBP65-R & AGGTATGGGCCATCTGTTGAC & 59.79 & \\
\hline ALP-F & GCAGCACTCCTTCCGGTATT & 60.11 & 156 \\
\hline ALP F-R & GTACAATCTTCACGCCCGGA & 60.11 & \\
\hline PPARr-F & ATTCGGCTAAAGCTGGCGTA & 59.82 & 106 \\
\hline $\operatorname{PPAR} \gamma-\mathrm{R}$ & TGCATTGTGTGACATCCCGA & 59.96 & \\
\hline
\end{tabular}

F, forward; R, reverse; OCN, osteocalcin; RUNX2, Runt-related transcription factor 2; LPL, lipoprotein lipase; COLI, collagen I; TLR4,

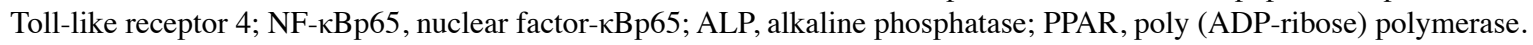

Stimulation and culture of hPDLCs. The cells were divided into a control group, TLR4 activation group (LPS-PG, $10 \mathrm{ng} / \mathrm{ml}, 24 \mathrm{~h}$ ), TLR4 antagonist group (TLR4 antagonist, $1 \mu \mathrm{g} / \mathrm{ml}, 24 \mathrm{~h}$ ), osteogenic induction control group, osteogenic induction and agonist group, and osteogenic induction and antagonist group. Each group of cells were cultured in $\alpha$-MEM medium (D-glucose $1,000 \mathrm{mg} / \mathrm{l}, \mathrm{L}$-glutamine $292 \mathrm{mg} / \mathrm{l}$, sodium pyruvate $110 \mathrm{mg} / 1, \mathrm{NaHCO}_{3} 2200 \mathrm{mg} / 1$, Penicillin $100 \mathrm{U} / \mathrm{ml}$, Streptomycin $100 \mu \mathrm{g} / \mathrm{ml}, \mathrm{pH}$ 7.0-7.4) supplemented with 10\% FBS (Gibco; Thermo Fisher Scientific, Inc.), and placed in an incubator containing $5 \% \mathrm{CO}_{2}$ at $37^{\circ} \mathrm{C}$ in a saturated humidity.

Scratch assay. The back of a 6-well plate was marked with uniformly horizontal lines, separated by $0.5-1 \mathrm{~cm}$. Each well included at least five lines. The cells $\left(\sim 5 \times 10^{5}\right)$ were added to each well and incubated overnight. The following day, a pipette tip and ruler were used to scratch perpendicularly to the back horizontal line. The cells were washed three times with PBS, added to serum-free cell culture medium and incubated for $24 \mathrm{~h}$ in a $37^{\circ} \mathrm{C}$ incubator containing $5 \% \mathrm{CO}_{2}$. Images were captured by using an inverted phase microscope (Nikon Corporation, Tokyo, Japan) at 0, 24 and $48 \mathrm{~h}$.

Enzyme-linked immunosorbent assay (ELISA). Briefly, 96-well polysorp plates (Nalge Nunc International, Penfield, NY, USA) were coated with recombinant tubulin- $\alpha$-1c protein at a concentration of $10 \mu \mathrm{g} / \mathrm{ml}$ in $0.05 \mathrm{M}$ carbonate buffer at $4^{\circ} \mathrm{C}$ overnight. The wells were then washed with PBS containing $0.05 \%$ Tween-20 (PBS-T) four times and blocked with $3 \%$ BSA-PBS for $3.5 \mathrm{~h}$ at $37^{\circ} \mathrm{C}$. The samples were diluted at 1:100 with PBS-T containing 1\% BSA and were added to the 96-well plate. Wells filled with PBS-T containing $1 \%$ BSA without samples were set up to examine non-specific background. Following incubation for $1.5 \mathrm{~h}$ at $37^{\circ} \mathrm{C}$, the wells were washed six times with PBS-T. Subsequently, $100 \mu \mathrm{l}$ of goat anti-human IgG conjugated to peroxidase, (cat. no. 109-001-003; 1:5,000; Jackson Immunoresearch Laboratories, West Grove, PA, USA), was added to each well and incubated for $30 \mathrm{~min}$ at $37^{\circ} \mathrm{C}$. Following washing with PBS-T four times, the bound antibodies were detected with o-phenylenediamine as substrate. The reaction was terminated by adding $100 \mu \mathrm{l}$ of $2 \mathrm{M}$ sulfuric acid to each well. The values of absorbance were measured at $450 \mathrm{~nm}$ using a Bio-Rad plate reader.

Apoptosis detection. The cells were collected and re-suspended in PBS. The cells $\left(1 \times 10^{4}\right)$ were centrifuged at $700 \mathrm{x}$ g for $5 \mathrm{~min}$ at room temperature and the supernatant discarded. The cells were gently re-suspended by adding $500 \mu \mathrm{l}$ of Annexin V-FITC conjugate. The cells were then mixed and incubated at room temperature for $10 \mathrm{~min}$ in the dark. Following centrifugation at $700 \mathrm{x} \mathrm{g}$ for $5 \mathrm{~min}$ at room temperature, the supernatant was discarded and the cells were gently re-suspended by adding $500 \mu \mathrm{l}$ of Annexin V-FITC Binding Solution. Following this, $10 \mu 1$ of PI staining solution was added, followed by gentle mixing in an ice bath in the dark. Flow cytometry was then used for the detection of apoptosis.

Western blot analysis. Briefly, the cells were collected and lysed in RIPA buffer. The BCA method was used to detect protein concentration, and $30 \mu \mathrm{g}$ of protein was loaded onto 

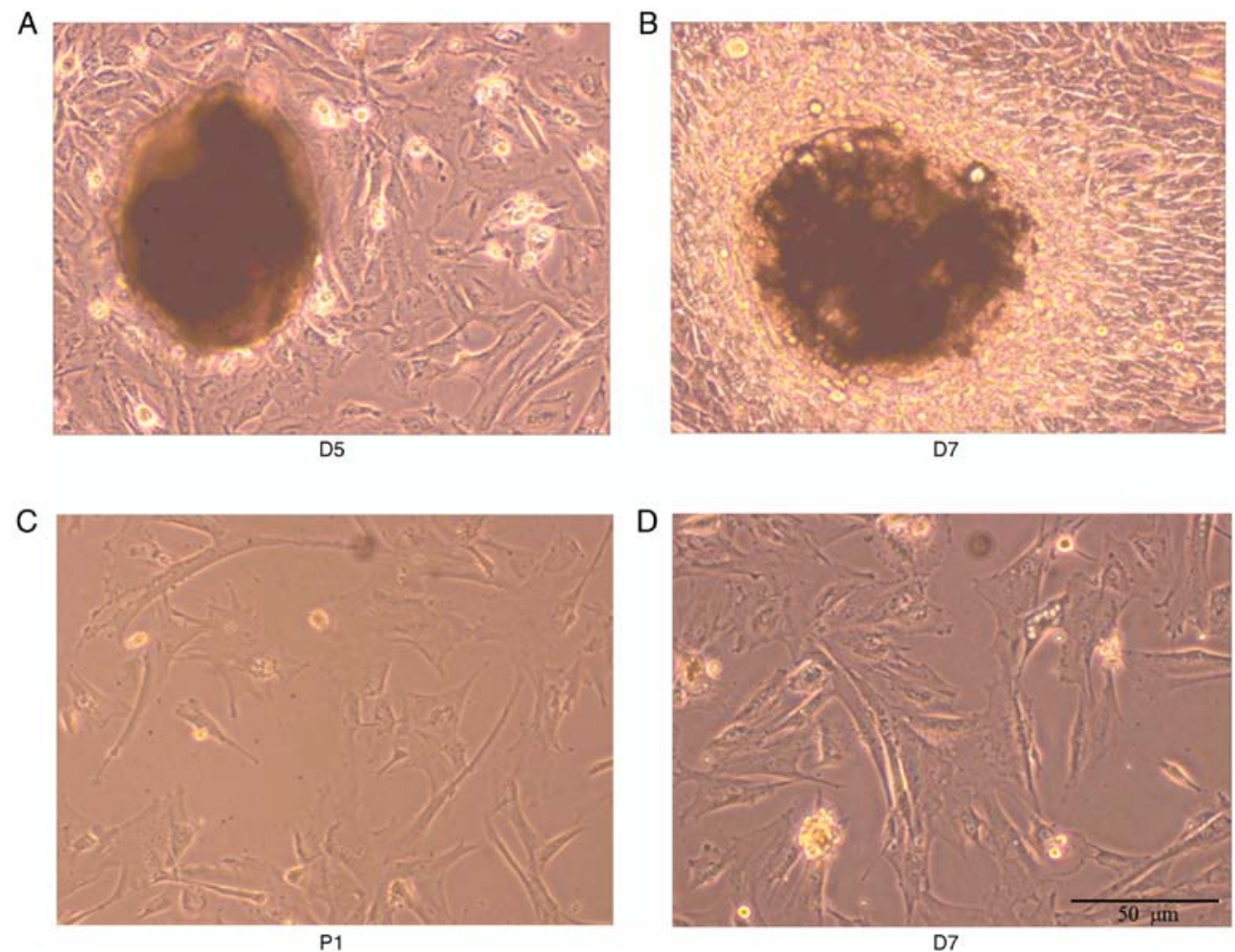

Figure 1. Isolation and culture of hPDLSCs from tissue blocks. Tissue blocks were cultured for (A) 5 days and (B) 7 days. Primary hPDLSCs sub-cultured for (C) P1 and (D) P2. hPDLSCs, human periodontal ligament stem cells; D, day; P, passage.

a $10 \%$ gradient SDS-PAGE gel. Following electrophoretic separation, the proteins were transferred onto an Immobilon-P membrane. The membranes were blocked with Super-Block Blocking Buffer, and probed with primary antibodies targeting NF-кBP65 (cat. no. sc-156137), TLR4 (cat. no. sc-293072), and GAPDH (cat. no. sc-47724; all 1:1,000; all from Santa Cruz Biotechnology, Inc.) followed by incubation with a secondary antibody conjugated to horseradish peroxidase (cat. no. sc-2354; 1:5,000; Santa Cruz Biotechnology, Inc.). The proteins were detected using the SuperSignal West Pico Chemiluminescent Substrate kit (Thermo Fisher Scientific, Inc.) and quantified using ImageJ Software (version 1.48; National Institutes of Health, Bethesda, MD, USA).

Statistical analysis. GraphPad Prism software version 6 (GraphPad Software, Inc., La Jolla, CA, USA) for Windows was used to complete the statistical analysis. The data are expressed as the mean \pm standard deviation. One-way analysis of variance was performed and followed by Tukey's multiple comparison post hoc test. $\mathrm{P}<0.05$ was considered to indicate a statistically significant difference.

\section{Results}

Isolation of hPDLSCs. As shown in Fig. 1A-D, from the 5th day of culture adhesion, cells emerged from the edge of the tissue block, most of which showed structures including long spindle-shaped or irregular polygons. Cells in the center of the tissue block were condensed, whereas peripheral cells were radial in growth. The cell body was full and the nucleus clear. With subculture, cell density was increased. The proliferation rates of the passage 1 and passage 2 cells were accelerated. Following inoculation at the ratio of $1: 3$, the appearance of the cells was monolayer cell fusion, and the cells were long spindle-shaped and arranged in bundles. The flow cytometry results (Fig. 2) showed that the expression levels of CD31, CD45, CD146, CD90, CD105, CD29 and Stro-1 in the negative control group were all $<1 \%$, and the indices of the hPDLSCs in the inflammatory groups (CD146, CD90, CD105, CD29 and Stro-1) were all positive, indicating that isolation of the hPDLSCs had been successful.

LPS induces the inflammation of hPDLSCs and increases the expression of TLR4. The expression levels of Stro-1 and keratin were detected by immunofluorescence. As shown in Fig. 3A and B, Stro-1 was positively expressed in the control and inflammation groups, whereas keratin was not expressed. The expression of Stro-1 in the control group was increased compared with that in the inflammation group, indicating that inflammation affected cell growth. In addition, the immunohistochemistry analysis showed that the expression of TLR4 was increased in the inflammation group (Fig. 3C). The MTT assay showed that the logarithmic cell growth phase was obtained between 3 and 8 days, whereas the stable growth phase was reached in 8-10 days (Fig. 4A). The absorbance in the inflammation group was lower than that in the control group, indicating that inflammation affected the cell proliferation rate. Flow cytometric analysis of the cell cycle (Fig. 4B and C) showed that the frequency of hPDLSCs in the G1 phase in the control group was higher than that in the inflammation group. By contrast, the frequency of hPDLSCs in the G2 phase was lower compared with that in the inflammation group, indicating that inflammation affected the 

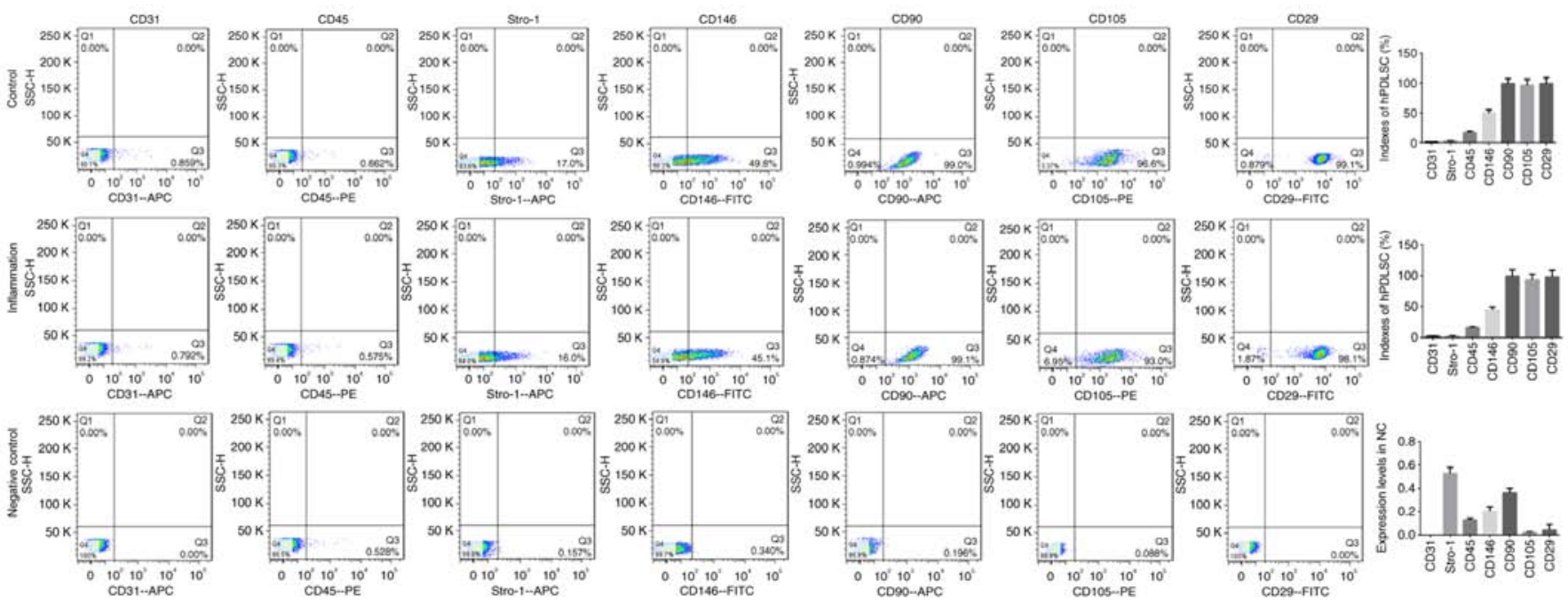

Figure 2. Identification and purification of hPDLSCs by flow cytometry. hPDLSCs, human periodontal ligament stem cells.
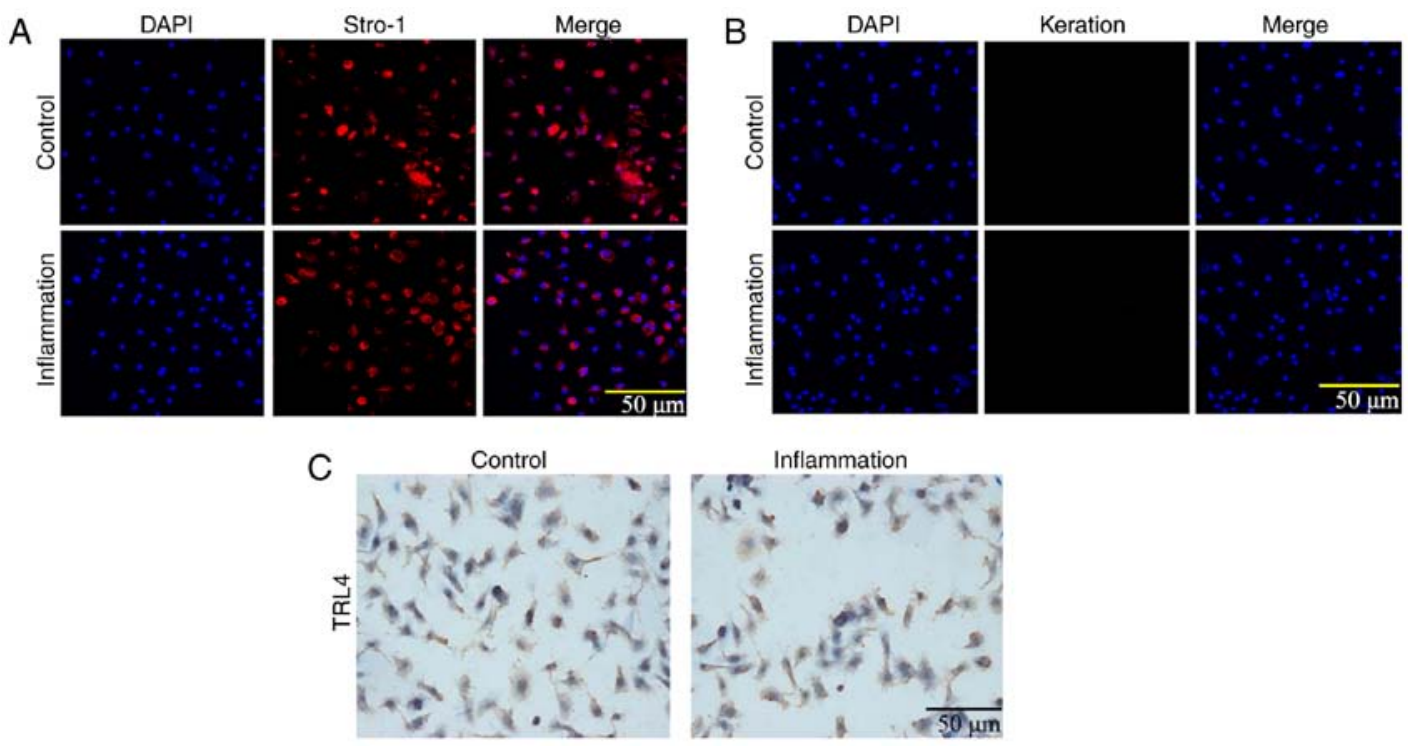

Figure 3. Immunofluorescence and immunohistochemistry of human periodontal ligament stem cells. (A) Positive staining of Stro-1. (B) Negative staining of keratin. (C) Positive staining of TLR4. TLR4, Toll-like receptor 4.

cell cycle. The Alizarin Red staining showed that hPDLSCs in the control and inflammation groups were positively stained and the number of calcium nodules in the control group was higher compared with that in the inflammation group (Fig. 4D), suggesting that inflammation inhibited osteogenic differentiation. The number of oil droplets in the control group was lower than that in the inflammation group (Fig. 4D), suggesting that there was induction of adipo-differentiation by LPS. The activity of ALP in the hPDLSCs in the control group was higher than that in the inflammation group, indicating decreased osteogenic differentiation in the inflammation group ( $\mathrm{P}<0.05$; Fig. $4 \mathrm{E})$. The RT-qPCR results indicated that the expression levels of OCN, Runx 2 and COL1 in the control group were higher than those in the inflammatory group, and the expression levels of the adipogenesis-related genes, including poly (ADP-ribose) polymerase (PPAR) $\gamma$ and lipoprotein lipase (LPL), were lower than those in the inflammatory group, indicating that the cells in the control group had higher osteogenic capacity than those in the inflammatory group, whereas lipogenic capacity was lower in the control group than in the inflammation group $(\mathrm{P}<0.05$; Fig. 4F).

Long-term TLR4 activation inhibits cell proliferation and migration but increases inflammation and apoptosis of hPDLSCs. The results of the MTT assay (Fig. 5A) showed that cell proliferation in the control group increased with time. Cell proliferation in the TLR4 activation group was increased between 0 and $48 \mathrm{~h}$ but decreased at $72 \mathrm{~h}$, indicating that TLR4 activation stimulated cell proliferation within a certain period of time, following which the proliferation ability was reduced. The scratch assay (Fig. 5B) showed that a large number of cells migrated into the scratch area in the control group, whereas fewer cells had migrated in the TLR4 activation group. In addition, in the TLR4 antagonist group, an increased number of cells was observed in the scratch area, but this was relatively lower than the control group. The ELISA 

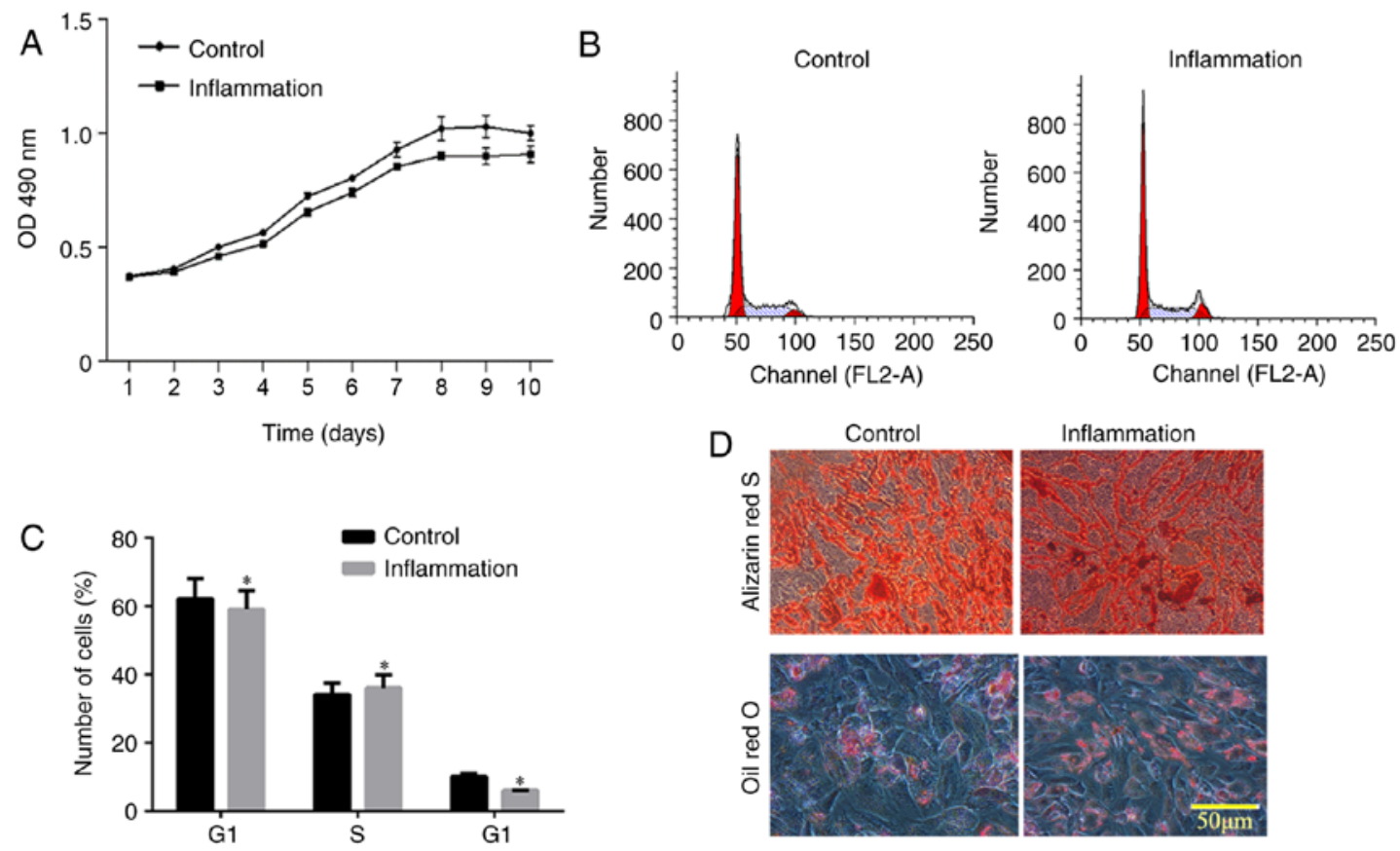

Inflammation
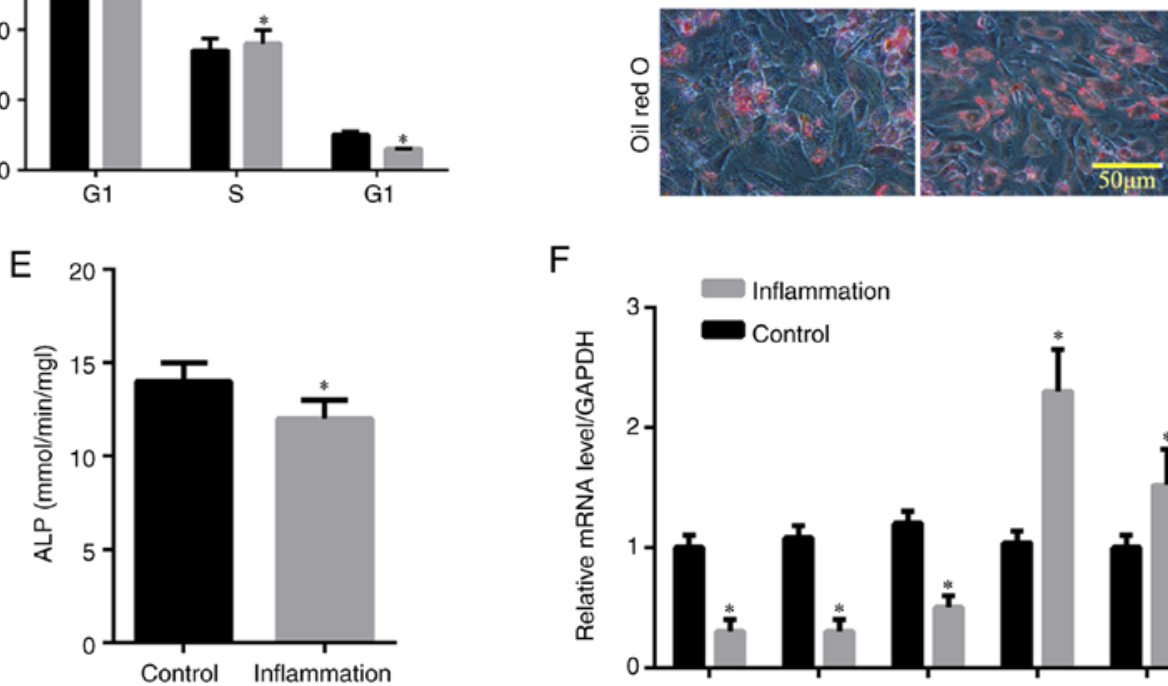

$\mathrm{F}$

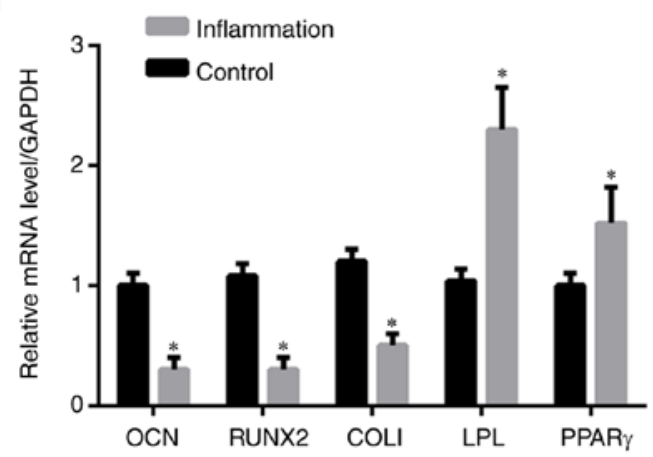

Figure 4. Effect of inflammation on human periodontal ligament stem cells. (A) Cell proliferation detected using an MTT assay; (B) cell cycle analysis; (C) distribution of cell cycle detected by flow cytometry; (D) pluripotency induction (osteogenic differentiation and adipogenic differentiation); (E) relative content of ALP; (F) relative content of osteogenic induction genes (OCN, Runx2 and COL1) and adipogenesis-related genes (PPAR $\gamma$ and LPL). " $\mathrm{P}<0.05$, vs. Control group. LPS, lipopolysaccharide; ALP, alkaline phosphatase; OCN, osteocalcin; Runx2, Runt-related transcription factor 2; Col1, collagen I; PPAR, poly (ADP-ribose) polymerase; LPL, lipoprotein lipase; D, day.

assay indicated that the concentrations of IL-1 $\beta$ and TNF- $\alpha$ in the TLR4 activation group were higher compared with those in the other groups $(\mathrm{P}<0.05$; Fig. $5 \mathrm{C})$. The levels of IL-1 $\beta$ and TNF- $\alpha$ in the control group were lower compared with those in the other groups. In the TLR4 antagonist group, the levels of IL-1 $\beta$ and TNF- $\alpha$ were higher than in the control group but lower that in the TLR4 activation group (Fig. 5C). The flow cytometric assay of apoptosis indicated that the apoptotic rate of cells in the TLR4 activation group was higher compared with the rates in the other groups $(\mathrm{P}<0.05)$, but the rate in the TLR4 antagonist group was higher compared with that in the control group (Fig. 5D). Therefore, TLR4 activation inhibits the proliferation and migration, but induces the inflammation and apoptosis of hPDLSCs.

NF- $\mathrm{BBP} 65 / T L R 4$ axis is involved in the osteogenic differentiation of $h P D L S C s$. In order to investigate the involvement of the NF-кBP65/TLR4 axis, western blotting was used to detect the expression of NF- $\kappa \mathrm{Bp} 65$ and TLR4 in the different groups. The expression levels of NF- $\kappa \mathrm{Bp} 65$ and TLR4 were increased in the TLR4 activation group compared with those in the other

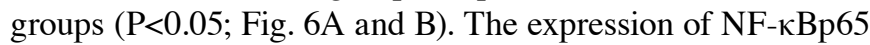
in the control group was significantly lower compared with that in the other groups. No significant difference in the expression of TLR4 was found between the TLR4 antagonist group and the control group. The number of Alizarin Red S-stained mineralized nodules in the LPS-induced cells cultured in normal medium in presence of TLR4 antagonist and in the control group was higher compared with that in the TLR4 agonist group (Fig. 6C). The same trend was observed in the osteogenic medium, in which the number of mineralized nodules was higher compared with that in the normal medium (Fig. 6C). The results of the RT-qPCR analysis confirmed that the expression of $\mathrm{NF}-\kappa \mathrm{Bp} 65$ in the TLR4 activation group was higher compared with that in the other groups $(\mathrm{P}<0.05)$ and the lowest expression levels were found in the control group. Compared with the control group, the expression levels of osteogenic genes (OCN, Runx2 and COL1) and ALP were decreased by treatment of the LPS-induced cells with TLR4 agonist, whereas the TLR4 antagonist reversed this 
A

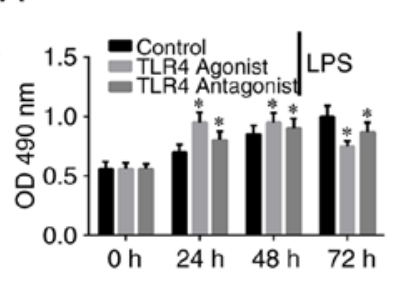

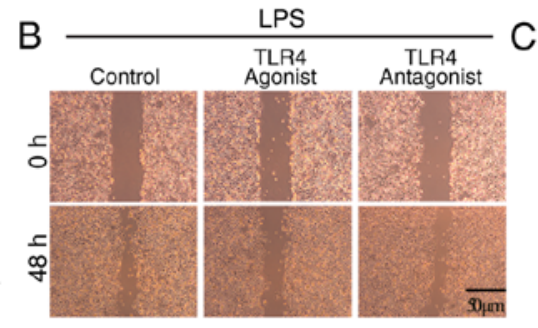
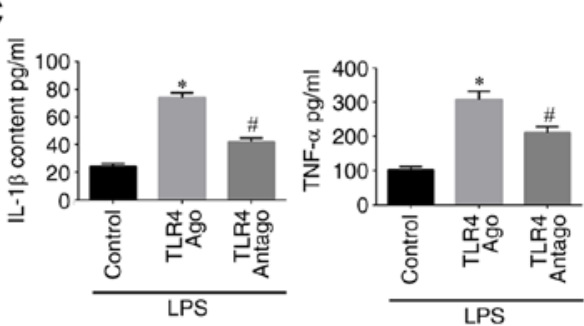
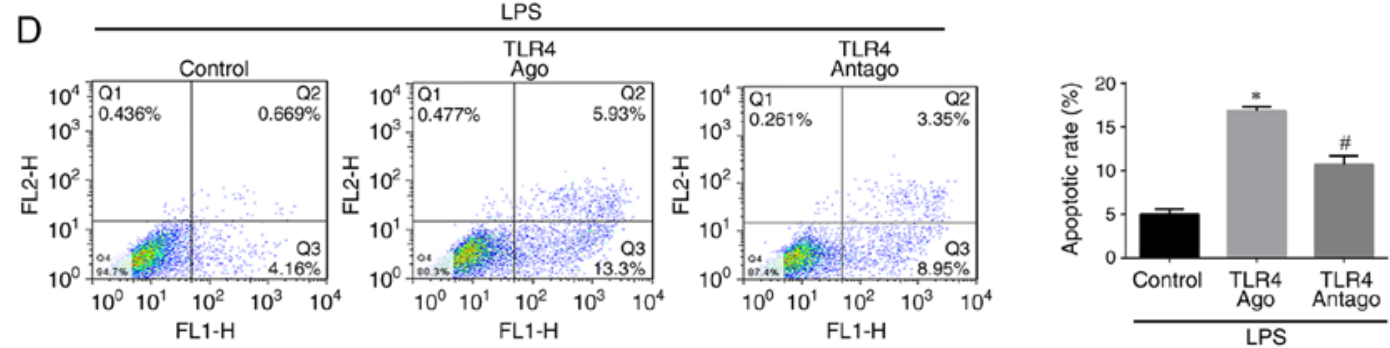

Figure 5. Functions of the TLR4 agonist and antagonist on hPDLSCs. Effects of the TLR4 agonist and antagonist on (A) cell proliferation and (B) cell migration. (C) Expression levels of IL- $1 \beta$ and TNF- $\alpha$. (D) Apoptosis of hPDLSCs detected by flow cytometry. ${ }^{*} \mathrm{P}<0.05$ vs. Control group; ${ }^{\mathrm{P}} \mathrm{P}<0.05$ vs. TLR4 Agonist group. hPDLSCs, human periodontal ligament stem cells; LPS, lipopolysaccharide; TLR4, Toll-like receptor 4.

A

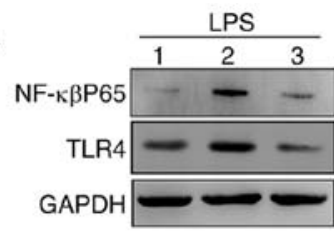

B

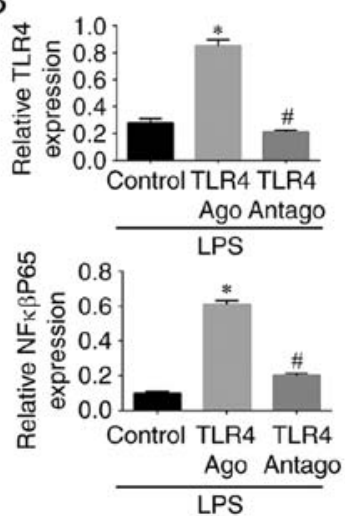

C
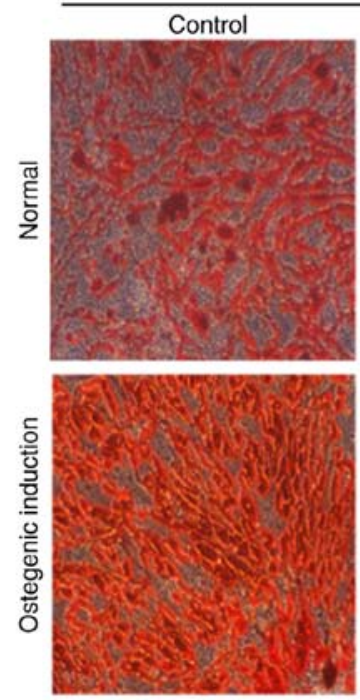

LPS
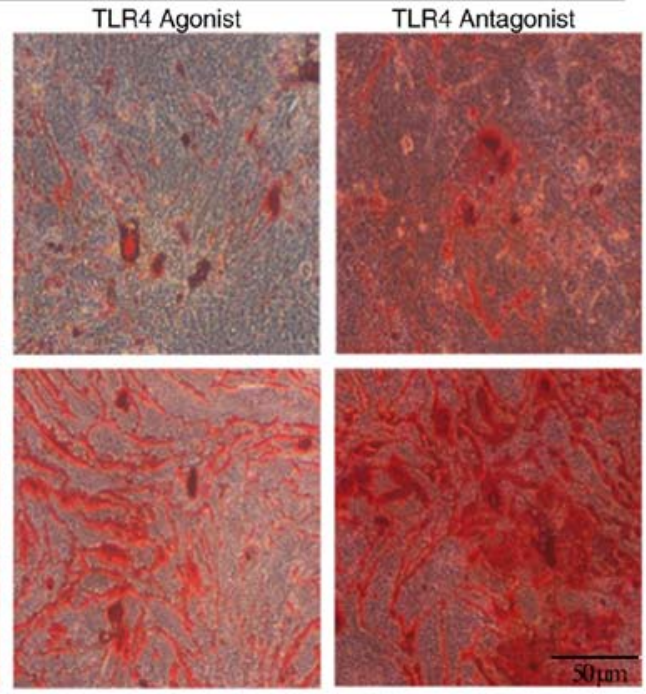

Figure 6. Effects of the TLR4 agonist and antagonist on the osteogenic differentiation of human periodontal ligament stem cells. (A) Expression of NF- $\kappa$ Bp65 and TLR4 (1, Control; 2, TLR4 agonist; 3, TLR4 antagonist). (B) Quantification of levels of NF- $\kappa$ Bp65 and TLR4. (C) Osteogenic differentiation ability was detected by staining with Alizarin Red. ${ }^{*} \mathrm{P}<0.05$ vs. Control group; ${ }^{\#} \mathrm{P}<0.05$ vs. TLR4 agonist group. NF- $\kappa \mathrm{Bp} 65$, nuclear factor- $\kappa \mathrm{Bp} 65$; TLR4, Toll-like receptor 4; LPS, lipopolysaccharide.

effect. The inverse results were observed for the adipogenic genes (PPAR $\gamma$ and LPL). Similar trends in the expression levels of these genes were recorded in the osteogenic induction medium $(\mathrm{P}<0.05$; Fig. 7). These results indicated that the NF- $\mathrm{kBp} 65 / \mathrm{TLR} 4$ axis is involved and may inhibit the osteogenic differentiation of hPDLSCs under inflammatory conditions.

\section{Discussion}

TLR4 is a known natural receptor for LPS, which is significantly increased in tissues with severe periodontitis, suggesting that TLR4 may be involved in periodontal tissue immune processes $(33,34)$. However, the regulatory role of the TLR4 signaling pathway in hPDLSCs under inflammatory conditions has not been elucidated. The present study aimed to investigate the functional role of TLR4 signaling in hPDLSCs induced with LPS. It was found that LPS induced inflammation of the hPDLSCs and increased the expression of TLR4 in the cell. Additionally, the TLR4 agonist decreased the levels of inflammatory markers in hPDLSCs and inhibited the osteogenic differentiation of these cells. Of note, the study revealed the NF-кBP65/TLR4 axis is a key regulatory pathway driving the osteogenic differentiation of hPDLSCs. 

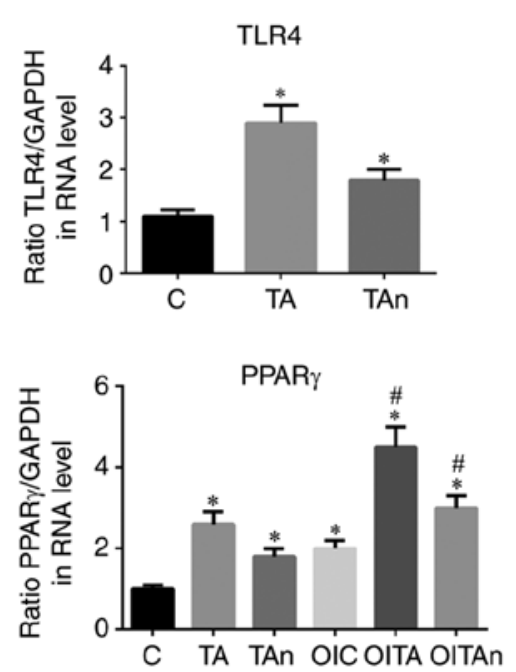
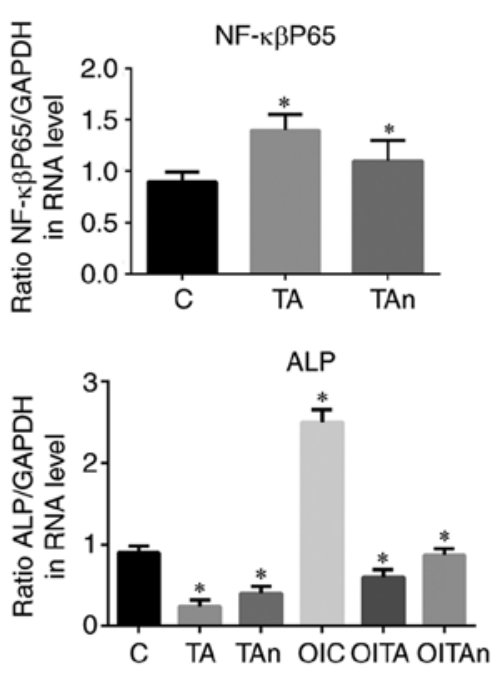
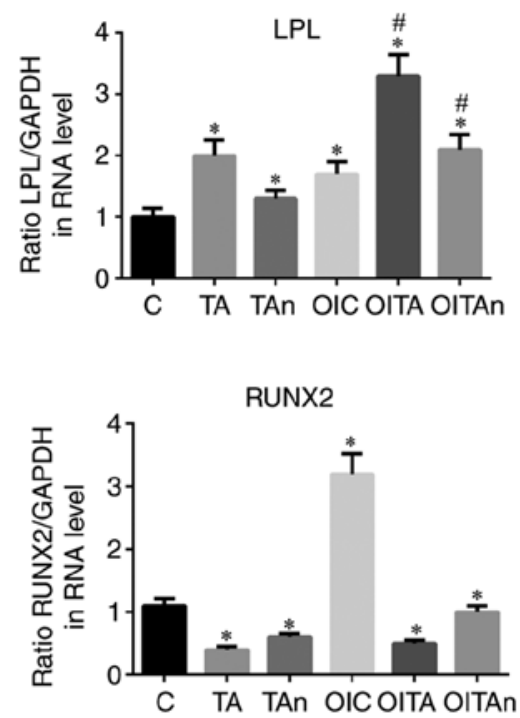
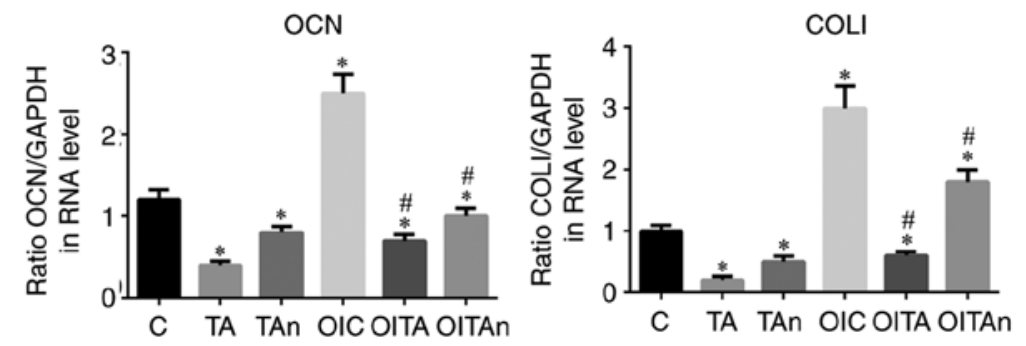

C: Control

TA: TLR4 Agonist

TAn: TLR4 Antagonist

OIC: Osteo Indu control

OITA: Osteo Indu TLR4 Ago

OITAn: Osteo Indu TLR4 Anta

Figure 7. Expression levels of osteogenic induction genes (OCN, Runx2 and COL1), adipogenesis-related genes (PPAR $\gamma$ and LPL), ALP, NF- $\kappa$ Bp65 and TLR4. ${ }^{*} \mathrm{P}<0.05$ vs. C group; ${ }^{~} \mathrm{P}<0.05$ vs. TA group. TLR4, Toll-like receptor 4; C, Control; TA, TLR4 agonist; Tan, TLR4 antagonist; OIC, osteogenic induction control; OITA, osteogenic induction TLR4 agonist; OITAn, osteogenic induction TLR4 antagonist; ALP, alkaline phosphatase; OCN, osteocalcin; Runx2, Runt-related transcription factor 2; Col1, collagen I; PPAR, poly (ADP-ribose) polymerase; LPL, lipoprotein lipase.

TNF- $\alpha$ and IL-1 $\beta$ are inflammatory factors produced downstream of TLR4. When TLR4 is specifically activated by LPS on hPDLSCs, its downstream signaling pathway is activated and expresses various inflammatory factors, including TNF- $\alpha$ and IL-1 $\beta$. Wang et al found a positive correlation between the expression of TLR4 and TNF- $\alpha$ on the surface of gingival fibroblasts (35). Additionally, they found that LPS of Porphyromonas gingivalis can be combined with TLR4 on the gingival fibroblast membrane to transmit intracellularly, stimulating gingival fibroblasts to produce inflammatory cytokines IL-1 and IL-6, which can activate osteoclasts and cause alveolar bone resorption. Sun et al found that the expression levels of TLR4 and IL-6 were significantly increased in hPDLSCs cultured in vitro following LPS stimulation (36). Similarly, Scheres et al found high mRNA expression levels of TLR4, TLR7 and CD14 in periodontitis on culturing periodontal cells in healthy and periodontitis groups (37). Chaudhari et al detected that the IL-1 $\beta$ content in the gingival tissues of patients with periodontitis was more than twice that of normal individuals, confirming that IL-1 $\beta$ is involved in the immune response, inflammation and alveolar bone resorption of periodontal tissues (38). The present study found that inflammation induced by LPS inhibited the osteogenic differentiation, proliferation and migration of hPDLSCs. In addition, it was found that only low levels of TNF- $\alpha$ and IL-1 $\beta$ were expressed in hPDLSCs under normal conditions. Following LPS stimulation, the expression levels of TNF- $\alpha$, IL- $1 \beta$ and NF- $\kappa B p 65$ increased with the increased expression of TLR4, indicating that LPS stimulated the hPDLSCs, and increased the expression of TLR4 and the release of inflammatory factors. These LPS-induced changes caused inflammatory damage, subsequently leading to periodontitis.

A limitation of the present study was that it did not examine whether treatment with the TLR4 antagonist prevented or reversed the harmful response induced by LPS or the agonist.

In conclusion, LPS-induced upregulation of the TLR4 signaling pathway induced the expression of proinflammatory cytokines IL-1 $\beta$, TNF- $\alpha$, NF- $\kappa$ BP65, and inhibited osteogenic differentiation, but induced adipogenesis of the hPDLSCs. The NF- $\mathrm{KBP} 65 / T L R 4$ axis is a key regulatory pathway driving the osteogenic differentiation of hPDLSCs under inflammatory conditions, which can provide novel targets for controlling periodontal inflammation and immune response, and potentially novel methods for the clinical prevention and treatment of periodontal disease.

\section{Acknowledgements}

Not applicable.

\section{Funding}

The present study was supported by the Shanghai Health Bureau Youth Research Project (grant no. 20144Y0256), the Shanghai Medical Exploration Project (grant nos. 1641196201 and 17411972600), the National Natural Science Foundation 
of China (grant no. 81700974) and the Natural Science Foundation of Shanghai (grant no. 17ZR1432800).

\section{Availability of data and materials}

All data generated or analyzed during this study are included in this published article.

\section{Authors' contributions}

$\mathrm{BY}, \mathrm{QL}$ and MZ made substantial contributions to the conception and design of the research and acquisition of data. MZ made substantial contributions to the analysis and interpretation of data. BY and QL were involved in the drafting and revision of the manuscript and acquisition of funding. All authors read and approved the final manuscript.

\section{Ethics approval and consent to participate}

This study was approved by the Institutional Review Boards of Affiliated Stomatology Hospital of Tongji University (Shanghai, China). All procedures involving human participants were performed in accordance with the ethical standards of the Institutional Review Boards of Affiliated Stomatology Hospital of Tongji University, and with the 1964 Helsinki declaration and its later amendments or comparable ethical standards. Written informed consent was obtained from all individual participants included in the study.

\section{Patient consent for publication}

Not applicable.

\section{Competing interests}

The authors declare that they have no competing interests.

\section{References}

1. Kulkarni V, Bhatavadekar NB and Uttamani JR: The effect of nutrition on periodontal disease: A systematic review. J Calif Dent Assoc 42: 302-311, 2014.

2. Al-Ghutaimel H, Riba H, Al-Kahtani S and Al-Duhaimi S: Common periodontal diseases of children and adolescents. Int J Dent 2014: 850674, 2014.

3. AlJehani YA: Risk factors of periodontal disease: Review of the literature. Int J Dent 2014: 182513, 2014.

4. Liu N, Gu B, Liu N, Nie X, Zhang B, Zhou X and Deng M: Wnt/ $\beta$-catenin pathway regulates cementogenic differentiation of adipose tissue-deprived stem cells in dental follicle cell-conditioned medium. PLoS One 9: e93364, 2014.

5. Tran Hle B, Doan VN, Le HT and Ngo LT: Various methods for isolation of multipotent human periodontal ligament cells for regenerative medicine. In Vitro Cell Dev Biol Anim 50: 597-602, 2014.

6. Yang H, Gao LN, An Y, Hu CH, Jin F, Zhou J, Jin Y and Chen FM: Comparison of mesenchymal stem cells derived from gingival tissue and periodontal ligament in different incubation conditions. Biomaterials 34: 7033-7047, 2013.

7. Silvério KG, Rodrigues TL, Coletta RD, Benevides L, Da Silva JS, Casati MZ, Sallum EA and Nociti FH Jr: Mesenchymal stem cell properties of periodontal ligament cells from deciduous and permanent teeth. J Periodontol 81: 1207-1215, 2010.

8. Kadar K, Kiraly M, Porcsalmy B, Molnar B, Racz GZ, Blazsek J, Kallo K, Szabo EL, Gera I, Gerber G and Varga G: Differentiation potential of stem cells from human dental origin-promise for tissue engineering. J Physiol Pharmacol 60 Suppl 7: 167-175, 2009.
9. Seo BM, Miura M, Gronthos S, Bartold PM, Batouli S, Brahim J, Young M, Robey PG, Wang CY and Shi S: Investigation of multipotent postnatal stem cells from human periodontal ligament. Lancet 364: 149-155, 2004.

10. Wang L, Shen H, Zheng W, Tang L, Yang Z, Gao Y, Yang Q, Wang C, Duan Y and Jin Y: Characterization of stem cells from alveolar periodontal ligament. Tissue Eng Part A 17: 1015-1026, 2011.

11. Park JC, Kim JM, Jung IH, Kim JC, Choi SH, Cho KS and Kim CS: Isolation and characterization of human periodontal ligament (PDL) stem cells (PDLSCs) from the inflamed PDL tissue: In vitro and in vivo evaluations. J Clin Periodontol 38: 721-731, 2011.

12. Diomede F, Caputi S, Merciaro I, Frisone S, D'Arcangelo C, Piattelli A and Trubiani O: Pro-inflammatory cytokine release and cell growth inhibition in primary human oral cells after exposure to endodontic sealer. Int Endod J 47: 864-872, 2014.

13. Zhang J, An Y, Gao LN, Zhang YJ, Jin Y and Chen FM: The effect of aging on the pluripotential capacity and regenerative potential of human periodontal ligament stem cells. Biomaterials 33: 6974-6986, 2012.

14. Monsarrat P, Vergnes JN, Nabet C, Sixou M, Snead ML, Planat-Bénard V, Casteilla L and Kémoun P: Concise review: Mesenchymal stromal cells used for periodontal regeneration: A systematic review. Stem Cells Transl Med 3: 768-774, 2014.

15. Koori K, Maeda H, Fujii S, Tomokiyo A, Kawachi G, Hasegawa D, Hamano S, Sugii H, Wada N and Akamine A: The roles of calcium-sensing receptor and calcium channel in osteogenic differentiation of undifferentiated periodontal ligament cells. Cell Tissue Res 357: 707-718, 2014.

16. Navabazam AR, Sadeghian Nodoshan F, Sheikhha MH, Miresmaeili SM, Soleimani M and Fesahat F: Characterization of mesenchymal stem cells from human dental pulp, preapical follicle and periodontal ligament. Iran J Reprod Med 11: 235-242, 2013.

17. Liu W, Konermann A, Guo T, Jäger A, Zhang L and Jin Y: Canonical Wnt signaling differently modulates osteogenic differentiation of mesenchymal stem cells derived from bone marrow and from periodontal ligament under inflammatory conditions. Biochim Biophys Acta 1840: 1125-1134, 2014.

18. Ozer A, Yuan G, Yang G, Wang F, Li W, Yang Y, Guo F, Gao Q, Shoff L, Chen Z, et al: Domain of dentine sialoprotein mediates proliferation and differentiation of human periodontal ligament stem cells. PLoS One 8: e81655, 2013.

19. Park CH, Rios HF, Jin Q, Sugai JV, Padial-Molina M, Taut AD, Flanagan CL, Hollister SJ and Giannobile WV: Tissue engineering bone-ligament complexes using fiber-guiding scaffolds. Biomaterials 33: 137-145, 2012.

20. Ding G, Liu Y, Wang W, Wei F, Liu D, Fan Z, An Y, Zhang C and Wang S: Allogeneic periodontal ligament stem cell therapy for periodontitis in swine. Stem Cells 28: 1829-1838, 2010.

21. Park CH, Rios HF, Jin Q, Bland ME, Flanagan CL, Hollister SJ and Giannobile WV: Biomimetic hybrid scaffolds for engineering human tooth-ligament interfaces. Biomaterials 31 : 5945-5952, 2010.

22. Xie $\mathrm{H}$ and Liu $\mathrm{H}$ : A novel mixed-type stem cell pellet for cementum/periodontal ligament-like complex. J Periodontol 83: 805-815, 2012.

23. Li Z, Jiang CM, An S, Cheng Q, Huang YF, Wang YT, Gou YC, Xiao L, Yu WJ and Wang J: Immunomodulatory properties of dental tissue-derived mesenchymal stem cells. Oral Dis 20: 25-34, 2014.

24. Kawasaki $\mathrm{T}$ and Kawai $\mathrm{T}$ : Toll-like receptor signaling pathways. Front Immunol 5: 461, 2014.

25. Hemmati F, Ghasemi R, Mohamed Ibrahim N, Dargahi L, Mohamed Z, Raymond AA and Ahmadiani A: Crosstalk between insulin and Toll-like receptor signaling pathways in the central nervous system. Mol Neurobiol 50: 797-810, 2014.

26. He Q, Wang L, Wang F and Li Q: Role of gut microbiota in a zebrafish model with chemically induced enterocolitis involving toll-like receptor signaling pathways. Zebrafish 11: 255-264, 2014.

27. Potnis PA, Dutta DK and Wood SC: Toll-like receptor 4 signaling pathway mediates proinflammatory immune response to cobalt-alloy particles. Cell Immunol 282: 53-65, 2013.

28. Guijarro-Muñoz I, Compte M, Álvarez-Cienfuegos A, Álvarez-Vallina L and Sanz L: Lipopolysaccharide activates Toll-like receptor 4 (TLR4)-mediated NF- $\mathrm{BB}$ signaling pathway and proinflammatory response in human pericytes. J Biol Chem 289: 2457-2468, 2014. 
29. Hunt JJ, Astley R, Wheatley N, Wang JT and Callegan MC: TLR4 contributes to the host response to Klebsiella intraocular infection. Curr Eye Res 39: 790-802, 2014.

30. Zhang P, Liu W, Peng Y, Han B and Yang Y: Toll like receptor 4 (TLR4) mediates the stimulating activities of chitosan oligosaccharide on macrophages. Int Immunopharmacol 23: 254-261, 2014.

31. Diomede F, Zingariello M, Cavalcanti MFXB, Merciaro I, Pizzicannella J, De Isla N, Caputi S, Ballerini P and Trubiani O: MyD88/ERK/NFkB pathways and pro-inflammatory cytokines release in periodontal ligament stem cells stimulated by Porphyromonas gingivalis. Eur J Histochem 61: 2791, 2017.

32. Livak KJ and Schmittgen TD: Analysis of relative gene expression data using real-time quantitative PCR and the 2(-Delta Delta C(T)) method. Methods 25: 402-408, 2001.

33. Qureshi ST, Larivière L, Leveque G, Clermont S, Moore KJ, Gros P and Malo D: Endotoxin-tolerant mice have mutations in Toll-like receptor 4 (Tlr4). J Exp Med 189: 615-625, 1999.

34. Sakai A, Ohshima M, Sugano N, Otsuka K and Ito K: Profiling the cytokines in gingival crevicular fluid using a cytokine antibody array. J Periodontol 77: 856-864, 2006.

35. Wang PL,Oido-MoriM,FujiiT,KowashiY,Kikuchi M,Suetsugu Y, Tanaka J, Azuma Y, Shinohara M and Ohura K: Heterogeneous expression of Toll-like receptor 4 and downregulation of Toll-like receptor 4 expression on human gingival fibroblasts by Porphyromonas gingivalis lipopolysaccharide. Biochem Biophys Res Commun 288: 863-867, 2001.
36. Sun Y, Shu R, Zhang MZ and Wu AP: Toll-like receptor 4 signaling plays a role in triggering periodontal infection. FEMS Immunol Med Microbiol 52: 362-369, 2008.

37. Scheres N, Laine ML, Sipos PM, Bosch-Tijhof CJ, Crielaard W, de Vries TJ and Everts V: Periodontal ligament and gingival fibroblasts from periodontitis patients are more active in interaction with Porphyromonas gingivalis. J Periodontal Res 46: 407-416, 2011

38. Chaudhari AU, Byakod GN, Waghmare PF and Karhadkar VM: Correlation of levels of interleukin- $1 \beta$ in gingival crevicular fluid to the clinical parameters of chronic periodontitis. J Contemp Dent Pract 12: 52-59, 2011.

This work is licensed under a Creative Commons Attribution-NonCommercial-NoDerivatives 4.0 International (CC BY-NC-ND 4.0) License. 